\title{
Correction to: Land Use Land Cover Dynamics Using Remote Sensing and GIS Techniques in Western Doon Valley, Uttarakhand, India
}

\author{
Ajay Kumar Taloor, Vaibhav Kumar, Vivek Kumar Singh, \\ Anil Kumar Singh, Ravindra V. Kale, Rahul Sharma, \\ Varun Khajuria, Girish Raina, Beena Kouser, \\ and Naveed Hassan Chowdhary
}

\section{Correction to:}

Chapter 4 in: S. Sahdev et al. (eds.), Geoecology of Landscape Dynamics, Advances in Geographical and Environmental Sciences, https://doi.org/10.1007/978-981-15-2097-6_4

In the original version of the book, the following belated correction has been incorporated: The incorrect affiliation of authors "A. K. Singh and R. V. Kale" has now been replaced with the correct affiliations as in below:

A. K. Singh Agromet Advisory Services Division, Indian Meteorological Department, New Delhi 110003, India e-mail: singhanil854@gmail.com

R. V. Kale Western Himalayan Regional Center, National Institute of Hydrology, (Ministry of Water Resources, River Development and Ganga Rejuvenation, Govt. of India) Irrigation \& Flood Control Complex, Opposite Military Hospital, Satwari, Jammu Cantt., Jammu 180003, India e-mail: ravikale2610@gmail.com

The erratum chapter and the book have been updated with the change.

The updated version of this chapter can be found at https://doi.org/10.1007/978-981-15-2097-6_4 